\title{
The perspectives of older women with chronic neck pain on perceived effects of qigong and exercise therapy on aging: a qualitative interview study
}

\author{
This article was published in the following Dove Press journal: \\ Clinical Interventions in Aging \\ 3 March 2014 \\ Number of times this article has been viewed
}

\author{
Christine Holmberg ${ }^{1,2}$ \\ Julia Rappenecker' \\ Julia J Karner' \\ Claudia MWitt ${ }^{1,3}$ \\ 'Institute for Social Medicine, \\ Epidemiology, and Health Economics, \\ ${ }^{2}$ Berlin School of Public Health, \\ Charité - Universitätsmedizin \\ Berlin, Berlin, Germany; ${ }^{3}$ Center \\ for Complementary and Integrative \\ Medicine, University Hospital Zurich, \\ Zurich, Switzerland
}

\begin{abstract}
Chronic pain is prevalent in elderly populations. The goals of this study were 1) to understand the results of a randomized clinical trial - Qigong and Exercise Therapy for Elderly Patients with Chronic Neck Pain (QIBANE) - that showed no difference between qigong, exercise therapy, and no-treatment on quality of life, and 2) to understand how elderly individuals with chronic pain experience interventions of qigong and exercise therapy. A qualitative interview study was conducted with 20 QIBANE participants. Interviews asked about motivation for and expectations of trial participation, experiences with the exercise classes (qigong or exercise therapy), and changes in pain experience. Interviews were transcribed, entered into the software program ATLAS.ti, and coded thematically by two coders. Content analysis was performed. All interviewees reflected positively on their QIBANE experience and described their participation in QIBANE as helpful. However, what was discussed in both groups when they talked about "positive experiences" in the study differed between the two groups. For example, themes that emerged in the exercise-therapy group related to difficulties associated with aging and staying physically active. In the interviews with qigong group members, emergent themes related to qigong as a method that improved bodily experiences and influenced daily activities. The effects that exercise therapy and qigong have on an elderly population cannot be captured by health-related quality-of-life measurements, such as the Short Form (36) Health Survey. Broader concepts of quality of life that include the concepts of self-efficacy and positive affect may be more appropriate. The results presented in this study suggest that for this population group, the approach of patient-centered outcomes is especially pertinent in order to design meaningful intervention studies in the elderly. This means that research questions, interventions, and outcome measurements need to take into account the special situation of elderly people.
\end{abstract}

Keywords: qigong, exercise therapy, neck pain, back pain, women

\section{Introduction}

A higher degree of physical activity, past and present, has been associated with increased life satisfaction and health-related quality of life in older adults and a later onset of physical and mental diseases. ${ }^{1-9}$ For elderly populations, it has been suggested that qigong and tai chi may be particularly useful because of the meditative movements with which they work. ${ }^{10,11}$ Both therapies can be considered mind-body therapies that aim to control and harmonize breath, body, and mind consciously. ${ }^{12}$ In order to support an uninterrupted flow of energy through the body, qigong uses periodic, flowing body movements. Qigong and tai chi have been shown to improve physical function and
Correspondence: Christine Holmberg Institute for Social Medicine, Epidemiology, and Health Economics, Charité Universitätsmedizin Berlin, 57 Luisenstrasse, Berlin 10117, Germany Tel +4930450529 192

Fax +49 30450529917

Email christine.holmberg@charite.de 
reduce fall risk and blood pressure in aging populations. ${ }^{11}$ Qigong also has been shown to improve chronic pain in younger populations. ${ }^{13,14}$ Surprisingly, evidence has not yet been established that qigong or other mind-body interventions may improve chronic pain in the elderly. ${ }^{15-17}$ We conducted a randomized controlled trial (RCT) that compared the effect of qigong, exercise therapy, and no-treatment (waiting list) on chronic neck pain in an elderly population (Qigong and Exercise Therapy for Elderly Patients with Chronic Neck Pain [QIBANE]). ${ }^{16,17}$ Exercise therapy in contrast to qigong focuses on particular body parts, such as the neck, and not on an entire system to alleviate specific symptoms. ${ }^{18}$ Exercise therapy aims to discover local dysfunctions, such as joint or muscle contractions, in order to suspend them by using manual or mechanical techniques. It is based on the anatomic knowledge of muscles, bones, and tissues and their interaction.

For the quantitative analyses of the outcomes, no significant effects were found for qigong or exercise therapy compared to no-treatment. This was equally true for the effect on neck pain and for the effect on health-related quality of life. ${ }^{16}$ These study results were surprising, because other studies in aging populations have demonstrated positive psychosocial effects for mind-body interventions, including qigong. ${ }^{10,19}$ Thus, to not find a difference in health-related quality of life, at least compared to the notreatment group, required explanation. In particular, some data from the 3-month follow-up assessment suggested that QIBANE participants had experienced positive effects, and the study had more than the necessary number of participants to detect a difference between the groups. After the intervention was completed, QIBANE participants were asked if they had decided to continue the classes at their own cost after study termination, and 58\% said they would. Of those, $40 \%$ were from the qigong intervention arm and $77 \%$ from the exercise-therapy group. In addition, it appeared unreasonable why an intervention that had shown effects on chronic pain in younger populations ${ }^{13,14}$ showed no effect in aging populations. ${ }^{16}$ Chronic pain of the neck in the elderly is a serious public health problem..$^{20,21,22-25}$ Thus, finding interventions to decrease neck pain that may also be beneficial for health-related quality of life would be very valuable. Qigong seemed such an appropriate intervention for elderly populations due to its meditative and gentle movements.

Thus, in the current study, we wanted to understand why the pain-reducing features of qigong that have been shown in younger populations could not be shown in QIBANE. ${ }^{16,17}$ The question is how older adults experience qigong and exercise therapy and what effects they perceive these therapies had on them.

\section{Materials and methods Study design}

To understand the experiences of older adults with qigong and exercise therapy, we conducted a qualitative interview study with 20 participants of QIBANE using maximum variation sampling. ${ }^{16}$ The interviews were semistructured and conducted one on one to enable interviewees to talk about their experiences and reflect upon them in a trusted and protected environment. Participants of the current study were selected to reflect the outcomes on the primary and secondary end points of the QIBANE population.

\section{Sample}

Selection for the sample for the interview study was based on the results of the primary end point of QIBANE. We wanted to ensure that the interview sample reflected the entire range of responses to the primary end point, which was decrease in neck pain as measured by the Visual Analog Scale (VAS). ${ }^{26}$ In addition, secondary end points, such as the Neck Pain and Disability Scale ${ }^{27}$ and the Short Form (36) Health Survey (SF-36), ${ }^{28}$ were also considered in developing a ranking list of QIBANE participants in each study arm as potential interview participants.

In order to achieve a diverse set of interview participants with regard to these end points, QIBANE participants were divided into groups of those with an improvement in neck pain, those with a worsening of pain, and those with no changes in comparison to the baseline assessments. Once the rankings were established, people on the list were called one after the other until ten participants from the qigong group and ten from the exercise-therapy group had agreed to a qualitative interview. Based on experiences from other qualitative studies, an overall sample of 20 participants was chosen to understand the experiences with qigong and exercise therapy. ${ }^{29,30}$

To reach the sample size of 20, 26 persons had to be contacted by telephone and asked for their consent to a home visit for the interview. Six refused participation in the interview study, because they did not want an interviewer to visit their home in case the phone call was a scam.

\section{Data collection}

The study team developed an interview guideline that was tested in preliminary interviews to assess if the 
information that was needed to answer the research question was being produced. The preliminary interviews were discussed within the research team and analyzed in joint team sessions. The final interview guideline included questions regarding motivation for and expectations of trial participation, experiences with the exercise classes (qigong or exercise therapy), changes in pain experience, and when applicable, why they decided to continue the class. All questions were open-ended. All interviews were conducted at the homes of the interviewees by researchers who were trained in qualitative interviewing. We suggested the homes of interviewees as study sites to accommodate study participants and to conduct the interviews in a well-known environment in which a relaxing and open atmosphere could develop easily ${ }^{31}$ to facilitate data collection. The duration of the interviews was 40 minutes on average.

\section{Data analysis}

The interviews were recorded, transcribed verbatim, and entered into ATLAS.ti (ATLAS.ti Scientific Software Development GmbH, Berlin, Germany), a software program developed to aid the coding process in qualitative research. Analysis was based on content analysis. ${ }^{32}$ Two researchers (JR, JK) who were not involved in data collection developed a coding system based on their readings of the interviews. To develop the coding system, both researchers first coded the same single interview independently. The two coded versions were compared and consolidated into one coding system. If differences existed in coding, these were discussed to ensure that every code was precisely defined. If there was an important quotation left without a corresponding code from the first coding round, a new code was added to the coding system. A final coding system was developed in group discussions within the interview study research team and within a qualitative research group at the Institute for Social Medicine, Epidemiology, and Health Economics. The qualitative research team consisted of epidemiologists, anthropologists, and medical doctors. These disciplines were supplemented by psychologists in the qualitative research group of the institute. This diverse set of disciplinary backgrounds allowed a thorough and comprehensive working through of materials and the establishment of a comprehensive coding system. After all the data were coded, one network for every code was created. The network displayed all quotations that were allocated to specific codes and the relations of the quotations to each other. A short text summarizing the content of every network was created. Subsequently, the codes were grouped in families for further analysis. Short notes (memos) were taken to record ideas as they arose throughout the entire process. Throughout the analysis process, the analysis was regularly presented and discussed in the qualitative study team $(\mathrm{CH}, \mathrm{JR}, \mathrm{JK}, \mathrm{CMW})$ and the qualitative research group to ensure intersubjectivity of analysis and results.

\section{Ethics statement}

The intervention study was approved by the ethics review board of the Charité Universitätsmedizin Berlin. Participants gave written and oral consent to the intervention study. The interview study was part of the intervention study. Selected participants were invited by phone to participate in an interview about their experiences with the RCT. The interviews took place at their homes, and they were asked to provide additional oral consent for a home visit. The consent process was documented in the case-report forms.

\section{Results}

In the content analysis, different themes emerged in the analysis of the interviews with members of the qigong intervention group versus members of the exercise-therapy intervention group. Overall, all interviewees reflected positively on their QIBANE experience, and all talked about their participation in QIBANE as helpful for them. However, what was discussed in both groups when they talked about "good" or "positive experiences" in the study differed between the two groups. For example, themes that emerged in the exercise-therapy group were difficulties associated with aging and to stay physically active. In the interviews with qigong group members, themes that emerged were qigong as a method as well as the influence of qigong on body awareness and how this influenced daily activities. In the following sections, we present these themes separately for each group. We then compare the different experiences.

\section{Study sample}

The study population consisted of women only. Overall, there were 20 women in the study. Among these, ten had participated in the exercise-therapy intervention arm in QIBANE and ten in the qigong intervention arm. The women had a mean age of 76.2 (standard deviation \pm 4.52 ) years. On average, they had $15.05( \pm 13.01)$ years of neck pain (Table 1). In QIBANE, nine of the participants had had a deterioration of neck pain 
Table I Sample sociodemographics

\begin{tabular}{|c|c|c|c|}
\hline Characteristics & $\begin{array}{l}\text { Qigong } \\
\text { group } \\
\text { Mean ( } \pm \text { SD) }\end{array}$ & $\begin{array}{l}\text { Exercise- } \\
\text { therapy group } \\
\text { Mean ( } \pm \text { SD) }\end{array}$ & $\begin{array}{l}\text { Combined } \\
\text { groups } \\
\text { Mean }( \pm S D)\end{array}$ \\
\hline Age, years & $77.9( \pm 3.33)$ & $74.5( \pm 4.90)$ & $76.2( \pm 4.52)$ \\
\hline $\begin{array}{l}\text { Duration of pain, } \\
\text { years }\end{array}$ & I4.I ( \pm 12.32$)$ & $16.0( \pm 13.59)$ & $15.05( \pm|3.0|)$ \\
\hline
\end{tabular}

Abbreviation: SD, standard deviation.

during study participation, as indicated on the comparison of baseline to follow-up assessment, and eleven had experienced an improvement (Table 2). Most of the interviewees had indicated that they wanted to continue the treatment (Table 3).

\section{Exercise-therapy group}

All interviewees in the exercise-therapy group perceived the regularity of exercise during QIBANE as important. More than half of them had experienced an improvement in their general physical constitution during their participation in QIBANE. Improvements included a reduction in experienced neck pain, others discussed an increased general well-being, and some felt that participation in the exercise therapy helped them maintain their physical abilities. The interviewees from the exercise-therapy group experienced their QIBANE participation as successful, mostly because it meant that they moved regularly.

"Exercise can't hurt. So I continue going to the exercise group." (PN3, 71 years old, wished to continue the exercise therapy in the group.)

In the narratives, the effects of exercise therapy related to participants' overall experience of bodily pain. Being elderly in this sample meant that pain was presented in different parts of the body and accompanied them throughout their daily experiences. They focused on such a general sense of pain in their evaluation of exercise therapy, rather than a specific effect on neck pain.
"The pain was reduced. I have strong pain in the lumbar region, and that pain was gone for some time." (PN7, 75 years old, wished to continue the exercise therapy in the group.)

"It did help me. I now exercise, and even though I am older, it improves. Of course, pain in the back does not disappear any more when one is older. But . . . [it can improve]." (PN10, 81 years old, wished to continue the exercise therapy in the group.)

"I really need it [the exercise], here in the neck and in the back. I have osteoporosis. Now I do those exercises that I learned in class every free minute I have. And it helps tremendously. One just has to do it regularly." (PN6, 79 years old, wished to continue the exercise therapy in the group.)

Such quotations were typical for the ways the women talked about the positive experience they had with the trial. They had their own agenda for participating in the study, which was not necessarily focused on neck pain as QIBANE was, but was based more broadly on their overall bodily experiences.

Two women resented the lack of improvement they experienced from the exercises.

"Did the pain change in your neck or in your back?"

"No, not really. Even though I always participated [in the exercises]. But I have to admit, doing something by myself is difficult for me. One does it a little and then one quits." (PN5, 67 years old, wished to continue the exercise therapy in the group.)

\section{Staying independent}

Overall, the fact that the interviewees exercised regularly during their time as QIBANE participants and many beyond the trial was enough for the women to evaluate the study positively. This is due to the fact that for the interviewees, moving regularly was an important factor for "staying independent." The interviews revealed what it meant for the

Table 2 Changes in measurements, between baseline and primary end point, of the interviewees

\begin{tabular}{llllll}
\hline Questionnaire & $\begin{array}{l}\text { Improvement, } \\
\text { ET (number of } \\
\text { patients) }\end{array}$ & $\begin{array}{l}\text { Improvement, } \\
\text { QG (number of } \\
\text { patients) }\end{array}$ & $\begin{array}{l}\text { Worsening, } \\
\text { ET (number of } \\
\text { patients) }\end{array}$ & $\begin{array}{l}\text { Improvement, } \\
\text { QG (number of } \\
\text { patients) }\end{array}$ \\
\hline VAS & 4 & 5 & 6 & 5 & $\begin{array}{l}\text { Missing } \\
\text { data }\end{array}$ \\
NPDS & 7 & 6 & 3 & 3 & 0 \\
SF-36 & 3 & 8 & 6 & 2 & 1 \\
ADS & 3 & 2 & 3 & 5 & 7 \\
\hline
\end{tabular}

Abbreviations: ET, exercise therapy; QG, qigong; VAS, Visual Analog Scale; NPDS, Neck Pain and Disability Scale; SF-36, Short Form (36) Health Survey (mental component summary scale); ADS, Common Depression Scale (Allgemeine Depressionsskala). 
Table 3 Patients' assessment of the treatment (qigong and exercise therapy)

\begin{tabular}{llll}
\hline & $\begin{array}{l}\text { Yes } \\
\text { (number of } \\
\text { patients) }\end{array}$ & $\begin{array}{l}\text { No } \\
\text { (number of } \\
\text { patients) }\end{array}$ & $\begin{array}{l}\text { Missing data } \\
\text { (number of } \\
\text { patients) }\end{array}$ \\
\hline $\begin{array}{l}\text { Recommendation } \\
\text { of the treatment } \\
\text { Interest in continuing } \\
\text { the treatment }\end{array}$ & 17 & $\mathrm{I}$ & 2 \\
\hline
\end{tabular}

women to grow old. The interviewees were afraid to lose their independence as a result of growing old. In the interviews, the women expressed their hope that regular exercise would halt and reduce physical deterioration for as long as possible.

“I don't want my daughter to sacrifice her entire leisure time for me. When she has a day off, she comes by, cleans my apartment and everything. [. . . I I always hope [that my health will improve], I won't give up that hope and I am always very eager to participate [in the exercises]." (PN9, 70 years old, wished to continue the exercise therapy in the group.)

Thus, when the women discussed their experiences with exercise therapy, what they talked about was what it means to become old and frail. Participating in QIBANE was one way to deal with aging.

All interviewees from the exercise-therapy group experienced a positive effect from the intervention they undertook. The quotes, though, highlight that these effects were diverse and not necessarily focused on intensity of neck pain, which was the primary end point of QIBANE. The intervention was seen as a means to tackle effects of aging by staying active.

\section{Qigong group}

In contrast to the interviews of the exercise-therapy group, the main themes that emerged in the interviews with qigong group members concerned qigong as a method and its influence on the daily physical experience of the body. Two interviewees explained that their initial feeling when they learned that they had been randomized to the qigong group was one of disappointment. They did not expect the subtle movements they performed in class to have any effects. However, this feeling changed quickly.

"Before [taking the course], I always thought that it is not possible that this will have effects on different issues in the body. [. . .] I enjoyed coming to the classes. I felt happier [while participating in the course]." (QG2, 76 years old, wished to continue qigong in the group.)
The women described how their participation in qigong was relaxing, and how the movements had effects on their psyche.

"It is very relaxing, the quietness. I really enjoyed the movements. And with these movements, one notices afterwards that one has been active, that it works some muscles, even though it feels so easy and relaxing while doing it." (QG3, 76 years old, wished to continue qigong in the group.)

"The qigong class influences the inner feelings and emotions more than the body. It seems to me like one works with that inner quietness that one is taught about in class." (QG4, 77 years old, wished to continue qigong in the group.)

Again, these intervention effects may not have been directly associated with the intensity of neck pain as measured by the VAS. As a whole, the participants' feedback emphasized more the overall effects that the participants experienced due to the exercise of qigong than their experiences of pain.

"I would really recommend it for overall well-being. One does not work hard; that is the marvelous part. It is so calm. One can relax, one can focus on one's inner being." (QG6, 85 years old, wished to continue qigong in the group.)

In addition to the calming effect and the focusing on one's inner being, interviewees described a comforting influence from the exercises on their overall existence in the world.

"[. . .] with time, I experienced how I became calmer and more in balance. I did not get angry that easily like I used to. So that really did me good." (QG5, 78 years old, no wish to continue qigong in the group.)

"It is strange that one can train one's body in such a way that one can experience things one never thought of or that there is such a deep connection with the legs. You know, with the soles of our feet, all the things that have meaning there. I have to say I really enjoyed learning qigong and I really liked it." (QG5, 78 years old, no wish to continue qigong in the group.)

The interviewees found their experiences challenging to articulate, emphasizing how qigong influenced them with descriptions such as "inner warmth," "oasis of tranquility," "relaxation," and "certain cheerfulness." One woman explicitly stated that it was very difficult to talk about the effects of qigong. She used terms such as "inner tranquilization" and "somehow feeling good." "Better feeling" and even "happier" were words used by many of the women to describe their experience. 


\section{Effects of qigong on daily living}

Interviewees also described a quality in the experience of their movements that differed from before their qigong practice, which they described as "flow," "aligned," and "smooth." They discussed changes in their breathing, decrease of vertigo, improvement of sleeping patterns, and feeling less cold.

"I sleep better. I am bad at explaining emotions, but there was an inner tranquility and a feeling of wellness. That has definitely appeared. [. . . I I have cold hands and feet. When I move, I notice how the flow moves and they become warmer. One feels warmer and sometimes also tired." (QG6, 85 years old, wished to continue qigong in the group.)

The interviewees partly attributed these changes to a different body awareness experienced through the practice of qigong. Changes could be very subtle, yet important in improving overall well-being.

"I learned to breathe differently. I used to breathe on the surface. And now when I breathe, I go outside on the balcony and bring in fresh air into the apartment. And I stand on the balcony and do breathing exercises. Deep breath deep into the belly. [. . . ] I really took away a lot from the course. Also, because one can do some simple exercises at all times, for example, if one does not feel so well. That is what I enjoy about qigong." (QG5, 78 years old, no wish to continue qigong in the group.)

"My mobility and flexibility overall has improved. I walk more upright. My entire posture changed through the qigong. I was more - confident is wrong - but that is how one noticed it. I always thought, 'you are walking like a young one again'.” (QG2, 76 years old, wished to continue qigong in the group.)

Thus, the exercises, albeit subtle, had profound effects on their experience of being old. These experiences had positive effects on other physical activities as well.

"Qigong helps relax the soul. That is what was the most important part for me. I became free and more open, also more flexible. I enjoyed walking more." (QG4, 77 years old, wished to continue qigong in the group.)

From the above descriptions, all of which were typical for qigong participants, it would appear that the interviewees' body awareness and perceptions changed through their experience of qigong. This in turn changed how they were in the world phenomenologically.

\section{Comparison of the experiences in the exercise-therapy and qigong groups}

The increasing frailness of old age was a challenge for all women in the study. However, it was mainly the women who had participated in the exercise therapy that discussed being worried that they may lose their independence due to lack of physical fitness. They talked about how their frailness impacted their everyday lives negatively. They increasingly needed the help of their families or friends. A few of them mentioned feelings of fear that they might not be able to handle everyday life anymore.

"I increasingly worry that I will fall. In fact, I am afraid of my increasing frailness. It didn't used to be like that. But increasingly I notice that, also, that my memory fades. Things I used to do without a problem are becoming a problem now." (PN8, 70 years old, wished to continue qigong in the group.)

In the interviews with women who practiced in the qigong group, aging and increasing frailness were less prominent as themes. The fear of falling was discussed by four of the interviewees from the qigong group. Indeed, two interviewees of the qigong group had an interesting perspective on their own older age. First, their point of reference in relation to their own frailty was that of their peers rather than younger people, and second, they discussed aging as a natural process that needed to be incorporated into one's plans. However, these particular views were not discussed in relation to their practice of qigong.

In the interviews of the qigong group, women talked more about the effects on body awareness and changing movements through the praxis than about aging-associated themes.

"I was skeptical in the beginning, and did not really want to participate. But when I finally did, I realized quickly that it did do me good. My whole well-being improved." (QG9, 73 years old, wished to continue qigong in the group.)

"My joy of life has definitely improved since I started qigong. Of course, I am optimistic by nature.” (QG4, 77 years old, wished to continue qigong in the group.)

Women in both groups participated in the exercises because they viewed them as a way to actively improve their well-being. They also appreciated exercising with peers who were in a similar age range and with similar abilities.

"Normally, I keep away from group exercises because I always think about the younger ones in the groups. But here it was in our residence, and all were about the same age. That made it enjoyable to do in the group." (PN8, 70 years old, wished to continue the exercise therapy in the group.) 
In all interviews, women described to us the ways in which the therapies helped them in their particular life circumstances. From the perspective of all interviewed women, QIBANE participation, regardless of which intervention arm they were in, was a positive experience.

\section{Discussion}

This qualitative interview study analyzed women's experiences as participants in either a qigong or an exercisetherapy group. The experiences the women expressed in the interviews reflect the methods of the physical intervention approaches. Exercise therapy focuses on a particular joint or a series of muscle contractions to relax them by manual or mechanical techniques. Similarly, the participants discussed their experiences with exercise therapy as specific bodily effects and increased mobility. Qigong as a therapy involves the entire body rather than particular parts of the body. Participants discussed an increase in body awareness, relaxation, and calmness, as well as positive effects on their emotions as a benefit of the therapeutic experience.

Thus, as the interviews from both groups showed, effects were discussed from a broader perspective, such as staying independent in old age through exercise or changes in one's being in the world, rather than as directly affecting pain intensity on the VAS. Based on the study findings, some of these effects were closely connected to what it meant to grow old and being an elderly person. For both groups, participating in QIBANE was a means to deal with aging and one they experienced as successful. Considering these factors, a more detailed look at why QIBANE showed no effects among the groups is warranted, not only in the VAS but also in health-related quality of life, as measured by the SF-36. However, the effect of physical activity on overall quality of life is a mediated effect of self-efficacy and positive affect that is achieved through physical activity. ${ }^{4,633,34}$ Neither of these concepts are part of the health-related quality-of-life SF-36 measurement that is commonly used in RCTs ${ }^{28}{ }^{2}$ But it is not only these two aspects that were missing in the SF-36. Issues related to aging which came to light during the interviews with participants of the exercisetherapy group, such as the concern for staying independent, would need to become part of health-related quality-of-life measures. As Borglin et al aptly describe, quality of life is a complex issue in older age. ${ }^{35}$ Participation in QIBANE was a means to satisfy body and mind, which resonates with the area "body and mind" that forms part of the quality-of-life concept identified by Borglin et al. ${ }^{35}$

It was clear from participants in both groups that physical activity per se was seen as a very positive way to tackle growing old. This importance of physical activity as a value in itself has been found in other studies in the elderly that focused on what it means to grow old. ${ }^{36,37}$

However, the way the two groups talked about their positive experiences as QIBANE participants differed. This may suggest that each intervention does produce specific effects. For the exercise-therapy group interviewees, the focus remained on effects of aging and the positive effects regular exercise has on negative aspects of aging. For the qigong interviewees, the focus was on the calming effects and the changes in body awareness in everyday life and overall mood. This may suggest that exercise therapy was perceived as successful because it targeted the concern of staying independent by providing the possibility of regular exercise. Qigong, though, had effects on other levels. While it was initiated for the same reasons, it seemed to shift the focus from concerns of staying independent to a focus and awareness on one's bodily sensations and bodily experiences in everyday life. Qigong and other mind-body therapies have been linked to perceived psychosocial benefits in studies on elderly populations. ${ }^{10}$ In these studies, the relaxing and calming effect as well as the positive influence on mood has been described for qigong. The effect on body awareness and the slight but significant changes in everyday life the women talked about has not yet been reported. It was very small constructs and effects that influenced the narratives of the interviewees profoundly. The broad focus of such healthrelated quality-of-life measures as the SF-36 cannot depict these phenomenological dimensions of living. Similarly, as we have shown, the classical clinical trial design with one primary end point on which a specific effect is measured does not reflect the reality of the elderly interviewees nor their motivation to participate in the RCT.

Outcome measurements in intervention studies with the elderly need to be developed with a focus on their perceptions and values, ${ }^{35}$ which include self-efficacy and positive affect. But they also need much smaller concepts that reflect the minute and subtle yet important changes described in this paper. Such concepts could include body awareness, pleasure for everyday activities, flexibility, and mood. Finally, such measurements need to be developed with an understanding of what it means to be old, and focus on the complex reality of the elderly.

\section{Acknowledgment}

This study was supported by a grant for the Chair for Complementary Medicine Research by the Carstens Foundation. 


\section{Disclosure}

The authors report no conflicts of interest in this work.

\section{References}

1. Achour EC, Barthelemy JC, Lionard KC, et al. Level of physical activity at the age of 65 predicts successful aging seven years later: the PROOF study. Rejuvenation Res. 2011;14(2):215-221.

2. Ahlskog JE, Geda YE, Graff-Radford NR, Petersen RC. Physical exercise as a preventive or disease-modifying treatment of dementia and brain aging. Mayo Clin Proc. 2011;86(9):876-884.

3. Sattler C, Erickson KI, Toro P, Schröder J. Physical fitness as a protective factor for cognitive impairment in a prospective population-based study in Germany. J Alzheimers Dis. 2011;26(4):709-718.

4. Motl RW, McAuley E. Physical activity, disability, and quality of life in older adults. Phys Med Rehabil Clin N Am. 2010;21(2):299-308.

5. Gretebeck RJ, Ferraro KF, Black DR, Holland K, Gretebeck KA. Longitudinal change in physical activity and disability in adults. Am J Health Behav. 2012;36(3):385-394.

6. White SM, Wójcicki TR, McAuley E. Physical activity and quality of life in community dwelling older adults. Health Qual Life Outcomes. 2009;7:10

7. Buchner DM. Physical activity and prevention of cardiovascular disease in older adults. Clin Geriatr Med. 2009;25(4):661-675, viii.

8. Paganini-Hill A. Lifestyle practices and cardiovascular disease mortality in the elderly: the leisure world cohort study. Cardiol Res Pract. 2011;2011:983764.

9. Balboa-Castillo T, León-Muñoz LM, Graciani A, Rodríguez-Artalejo F, Guallar-Castillón P. Longitudinal association of physical activity and sedentary behavior during leisure time with health-related quality of life in community-dwelling older adults. Health Qual Life Outcomes. 2011;9:47.

10. Rogers C, Keller C, Larkey LK. Perceived benefits of meditative movement in older adults. Geriatr Nurs. 2010;31(1):37-51.

11. Rogers CE, Larkey LK, Keller C. A review of clinical trials of tai chi and qigong in older adults. West J Nurs Res. 2009;31(2):245-279.

12. Dorcas A, Yung P. Qigong: harmonising the breath, the body and the mind. Complement Ther Nurs Midwifery. 2003;9(4):198-202.

13. Sitthipornvorakul E, Janwantanakul P, Purepong N, Pensri P, van der Beek AJ. The association between physical activity and neck and low back pain: a systematic review. Eur Spine J. 2011;20(5):677-689.

14. Lansinger B, Larsson E, Persson LC, Carlsson JY. Qigong and exercise therapy in patients with long-term neck pain: a prospective randomized trial. Spine (Phila Pa 1976). 2007;32(22):2415-2422.

15. Morone NE, Greco CM. Mind-body interventions for chronic pain in older adults: a structured review. Pain Med. 2007;8(4):359-375.

16. von Trott P, Wiedemann AM, Lüdtke R, Reishauer A, Willich SN, Witt CM. Qigong and exercise therapy for elderly patients with chronic neck pain (QIBANE): a randomized controlled study. J Pain. 2009;10(5):501-508.

17. Wiedemann AM, von Trott P, Lüdtke R, Reisszlihauer A, Willich SN, Witt CM. Developing a qigong intervention and an exercise therapy for elderly patients with chronic neck pain and the study protocol. Forsch Komplementmed. 2008;15(4):195-202.

18. Grotkasten S, Kienzerle H. Wirbelsäulengymnastik. Munich: Heyne; 2005.

Clinical Interventions in Aging

\section{Publish your work in this journal}

Clinical Interventions in Aging is an international, peer-reviewed journal focusing on evidence-based reports on the value or lack thereof of treatments intended to prevent or delay the onset of maladaptive correlates of aging in human beings. This journal is indexed on PubMed Central, MedLine, the American Chemical Society's 'Chemical Abstracts
19. Jahnke R, Larkey L, Rogers C, Etnier J, Lin F. A comprehensive review of health benefits of qigong and tai chi. Am J Health Promot. 2010;24(6): e1-e25.

20. Fernández-de-las-Peñas C, Hernández-Barrera V, Alonso-Blanco C, et al. Prevalence of neck and low back pain in community-dwelling adults in Spain: a population-based national study. Spine (Phila Pa 1976). 2011;36(3):E213-E219.

21. Strine TW, Hootman JM. US national prevalence and correlates of low back and neck pain among adults. Arthritis Rheum. 2007;57(4): 656-665.

22. Schuler M, Hestermann M, Hauer K, Schlierf G, Oster P. [Problems recognizing pain in geriatrics]. Schmerz. 2002;16(3):171-178. German.

23. Basler HD, Griessinger N, Hankemeier U, Märkert D, Nikolaus T, Sohn W. [Pain assessment and pain treatment in the geriatric patient. Part II: pain treatment]. Schmerz. 2005;19(1):65-73. German.

24. Basler HD, Hesselbarth S, Schuler M. [Pain assessment in the geriatric patient. Part I: pain diagnostics]. Schmerz. 2004;18(4):317-326. German.

25. Basler HD, Bloem R, Casser HR, et al. [A structured pain interview for geriatric patients]. Schmerz. 2001;15(3):164-171.

26. Lara-Muñoz C, De Leon SP, Feinstein AR, Puente A, Wells CK. Comparison of three rating scales for measuring subjective phenomena in clinical research. I. Use of experimentally controlled auditory stimuli. Arch Med Res. 2004;35(1):43-48.

27. Scherer M, Blozik E, Himmel W, Laptinskaya D, Kochen MM, Herrmann-Lingen C. Psychometric properties of a German version of the neck pain and disability scale. Eur Spine J. 2008;17(7):922-929.

28. Morfeld M, Bullinger M, Nantke J, Brähler E. [The version 2.0 of the SF-36 Health Survey: results of a population-representative study]. Soz Praventivmed. 2005;50(5):292-300.

29. Campbell R, Quilty B, Dieppe P. Discrepancies between patients' assessments of outcome: qualitative study nested within a randomised controlled trial. BMJ. 2003;326(7383):252-253.

30. Daley AJ, Copeland RJ, Wright NP, Wales JK. 'I can actually exercise if I want to; it isn't as hard as I thought': a qualitative study of the experiences and views of obese adolescents participating in an exercise therapy intervention. J Health Psychol. 2008;13(6):810-819.

31. Manderson L, Bennett E, Andajani-Sutjahjo S. The social dynamics of the interview: age, class, and gender. Qual Health Res. 2006;16(10): 1317-1334.

32. Mayring P. Qualitative Inhaltsanalyse: Grundlagen und Techniken. Weinheim: Beltz; 2010.

33. Konopack JF, McAuley E. Efficacy-mediated effects of spirituality and physical activity on quality of life: a path analysis. Health Qual Life Outcomes. 2012;10:57.

34. McAuley E, Doerksen SE, Morris KS, et al. Pathways from physical activity to quality of life in older women. Ann Behav Med. 2008;36(1): $13-20$.

35. Borglin G, Edberg AK, Rahm Hallberg I. The experience of quality of life among older people. J Aging Stud. 2005;19(2):201-220.

36. Bowling A. Perceptions of active ageing in Britain: divergences between minority ethnic and whole population samples. Age Ageing. 2009;38(6):703-710.

37. Kruschinski C, Theile G, Dreier SD, Hummers-Pradier E. The priorities of elderly patients suffering from dizziness: a qualitative study. Eur $J$ Gen Pract. 2010;16(1):6-11.

Service' (CAS), Scopus and the Elsevier Bibliographic databases. The manuscript management system is completely online and includes a very quick and fair peer-review system, which is all easy to use. Visit http://www.dovepress.com/testimonials.php to read real quotes from published authors. 